\title{
Microscopic Examination of a Corrosion Front in Spent Nuclear Fuel
}

Jeffrey A. Fortner, A. Jeremy Kropf, Robert J. Finch, and James C. Cunnane

Argonne National Laboratory, 9700 South Cass Avenue, Argonne, IL 60439

Spent uranium oxide nuclear fuel hosts a variety of trace chemical constituents, many of which must be sequestered from the biosphere during fuel storage and disposal. In this paper we present synchrotron $\mathrm{x}-$ ray absorption spectroscopy and microscopy findings that illuminate the resultant local chemistry of neptunium and plutonium within spent uranium oxide nuclear fuel before and after corrosive alteration in an air-saturated aqueous environment. We find the plutonium and neptunium in unaltered spent fuel to have a +4 oxidation state and an environment consistent with solid-solution in the $\mathrm{UO}_{2}$ matrix. During corrosion in an air-saturated aqueous environment, the uranium matrix is converted to uranyl $\mathrm{U}_{(\mathrm{VI}) \mathrm{O}_{2}{ }^{2+}}$ mineral assemblage that is depleted in plutonium and neptunium relative to the parent fuel. At the corrosion front interface between intact fuel and the uranyl-mineral corrosion layer, we find evidence of a thin $\left(\sim 20\right.$ micrometer) layer that is enriched in plutonium and neptunium within a predominantly $\mathrm{U}^{4+}$ environment. Available data for the standard reduction potentials for $\mathrm{NpO}^{2+} / \mathrm{Np}^{4+}$ and $\mathrm{UO}_{2}{ }^{2+} / \mathrm{U}^{4+}$ couples indicate that $\mathrm{Np}(\mathrm{IV})$ may not be effectively oxidized to $\mathrm{Np}(\mathrm{V})$ at the corrosion potentials of uranium dioxide spent nuclear fuel in air-saturated aqueous solutions.

Neptunium is an important radionuclide in dose contribution according to performance assessment models of the proposed U. S. repository at Yucca Mountain, Nevada. A scientific understanding of how the $\mathrm{UO}_{2}$ matrix of spent nuclear fuel impacts the oxidative dissolution and reductive precipitation of neptunium is needed to predict its behavior at the fuel surface during aqueous corrosion. Neptunium would most likely be transported as aqueous $\mathrm{Np}(\mathrm{V})$ species, but for this to occur it must first be oxidized from the $\mathrm{Np}(\mathrm{IV})$ state found within the parent spent nuclear fuel [1]. In the immediate vicinity of the spent fuel's surface the redox and nucleation behavior is likely to promote/enhance nucleation of $\mathrm{NpO}_{2}$ and $\mathrm{Np}_{2} \mathrm{O}_{5}$. Alternatively, $\mathrm{Np}$ may be incorporated into uranyl $\left(\mathrm{UO}_{2}{ }^{2+}\right)$ alteration phases [2]. In some cases, less-soluble elements such as plutonium will be enriched near the surface of the corroding fuel [3].

We have used focused synchrotron x-rays from the MRCAT beam line at the Advanced Photon Source (APS) at Argonne National Lab to examine a specimen of spent nuclear fuel that had been subject to 10 years of corrosion testing in an environment of humid air and dripping groundwater at $90^{\circ} \mathrm{C}$ [4]. We find evidence of a region, approximately 20 microns in thickness, enriched in plutonium and neptunium at the corrosion front that exists between the uranyl silicate alteration mineral rind and the unaltered uranium oxide fuel (Figures 1 and 2). The uranyl silicate is itself found to be depleted in these transuranic elements relative to their abundance relative to uranium in the parent fuel. This suggests a low mobility of these components owing to a resistance to oxidize further in the presence of a $\mathrm{UO}_{2}{ }^{2+} / \mathrm{U}^{4+}$ couple [5].

\section{References}

[1] A. J. Kropf, J. A. Fortner, R. J. Finch, J. C. Cunnane and C. Karanfil, Physica Scripta. Vol. T115, (2005) 998-1000.

[2] P. C. Burns, K. M. Deely, and S. Skanthakumar,. Radiochim. Acta 92, (2004) 151-159.

[3] E. C. Buck, P. A. Finn, and J. K. Bates, Micron 35 (2004) 235-243.

[4] R. J. Finch, E. C. Buck, P. A. Finn, and J. K. Bates, Mat. Res. Soc. Symp. Proc., Vol 556, (1999) 431438. 
[5] This work was funded by the U.S. Department of Energy (DOE), Office of Civilian Radioactive Waste Management, Yucca Mountain Program, and Office of Science and Technology and International, under Contract W-31-109-Eng-38. Work performed at MRCAT is supported, in part, by funding from DOE under grant number DEFG0200ER45811.

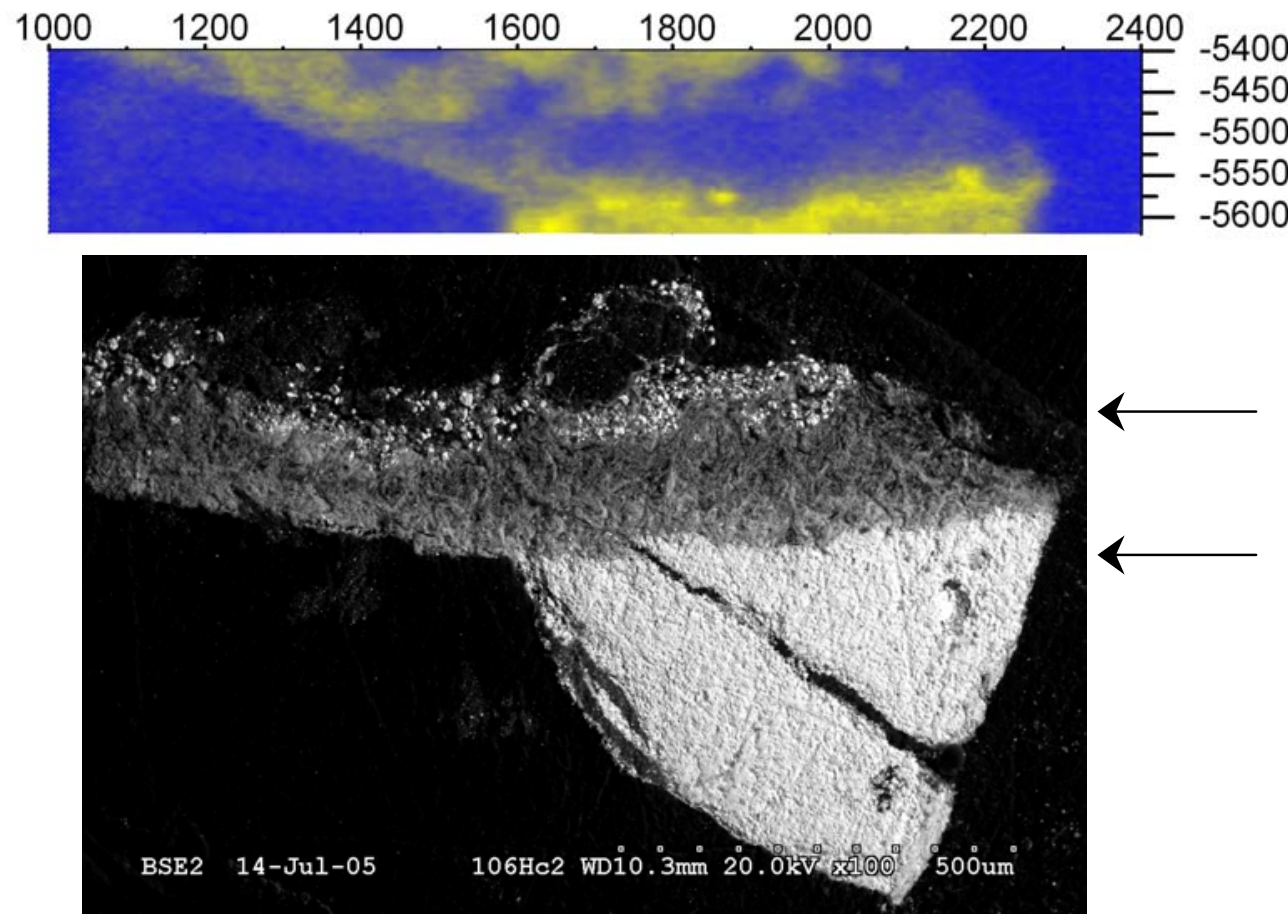

Figure 1. X-ray fluorescence map of the plutonium $\mathrm{L}_{\mathrm{III}}$ edge (above, with scale in microns) and backscattered SEM micrograph (below, at same approximate magnification) of cross-sectioned fragment of corroded spent nuclear fuel. The x-ray fluorescence map is rendered in false color, with yellow intensity indicating greater concentration of plutonium. The arrows to the right of the SEM micrograph indicate the approximate vertical range of the x-ray fluorescence scan. The uranyl silicate alteration mineral layer is clearly visible as a gray band atop the brighter uranium dioxide fuel matrix.

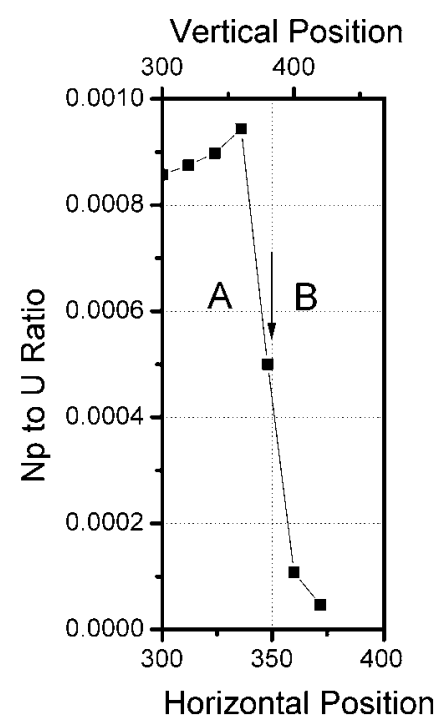

Figure 2. Neptunium $\mathrm{L}_{\text {III }}$ line scan across the fuel/alteration zone interface, showing distinct evidence of a weak, yet fairly broad ( 20 micron) zone that is enriched in neptunium. This enrichment, along with that of plutonium (Figure 1) occurs near the onset of a transition from quadravalent uranium [U(IV)] in the fuel to hexavalent uranium [U(VI)] that characterizes the alteration rind. Owing to its weak signal, a map of neptunium (present at 1 part in 2000 in the fuel) is not feasible. The findings provide further evidence that redox conditions near the corroding fuel surface control neptunium (and plutonium) oxidation and dissolution. 